\title{
Study of the $\mathrm{NdO}_{1.5}-\mathrm{TiO}_{2}-\mathrm{ZrO}_{2}$ ternary system of potential matrices for the immobilization of actinide wastes
}

\author{
Amina Sergeevna Ulanova, M S Nikolsky \\ IGEM, Moscow, Russian Federation; \\ ulanova-amina@mail.ru
}

One of the defining issues in the nuclear industry's long-term development is the long-term storage of high-level waste (HLW). Preserving matrices with a complex of unique physicomechanical and chemical properties should be used to immobilization HLW. Currently, aluminophosphate and borosilicate glasses are umsed as such matrices. Their disadvantages are low capacity for waste (415 wt.\%), High solubility in water, rapid crystallization, deterioration of protective properties over time. It is proposed to use crystal matrices as an alternative to glasses. The study of the ternary system $\mathrm{NdO}_{1.5}-\mathrm{TiO}_{2}-\mathrm{ZrO}_{2}$ is necessary to predict the compositions of ceramics promising as matrices for the rare-earth-actinide fraction of high-level waste (HLW). By solid-phase synthesis by sintering in a muffle furnace, 6 samples were obtained with a percentage along the line of $60 \mathrm{wt} \% \mathrm{NdO} 1.5$ with variable compositions of $\mathrm{TiO}_{2-}$ $\mathrm{ZrO}_{2}$, and 6 samples with a percentage along the line of $35 \mathrm{wt} \% \mathrm{NdO} 1.5$ with a variable composition of $\mathrm{TiO}_{2}-\mathrm{ZrO}_{2}$, at temperatures of $1450{ }^{\circ} \mathrm{C}$ and $1500{ }^{\circ} \mathrm{C}$.

The X-ray phase analysis was carried out on an Empyrean Malvern Panalytical X-ray powder diffractometer $(\mathrm{CuK} \alpha, 40 \mathrm{kV}, 20 \mathrm{~mA}$, $0.02^{\circ}$ step), a JSM_5610LV scanning electron microscope with a ULTIM MAX 100 energy dispersive spectrometer (SEM / EDS). The phase structure was determined by comparing the experimental X-ray diffraction patterns with the standards from the database. $\mathrm{X}$-ray phase analysis of the samples showed that at a temperature of $1450{ }^{\circ} \mathrm{C}$ for six samples with $60 \mathrm{wt} \% \mathrm{NdO} 1.5$ with variable $\mathrm{TiO}_{2}$ $\mathrm{ZrO}_{2}$ compositions, the formation of phases does not occur completely and require higher temperatures, and on the $35 \mathrm{wt} \% \mathrm{NdO} 1.513$ $\% \mathrm{ZrO}_{2}$ line and $52 \% \mathrm{TiO}_{2}$ is assumed to form a eutectic region. A preliminary SEM analysis confirmed this. More detailed results of the analysis of samples will be shown on the stand.

[1] Ulanova A.S., Marchenko E.I., Eremin N.N. «A new self-consistent interatomic potential set for structure modeling of monazites and xenotimes with variable composition», Minerals: Structure, Properties, Methods of Investigation, серия Springer Proceedings in Earth and Environmental Sciences. (2019)

[2] Muromtsev N.A., Eremin N.N., Ulanova A.S., Marchenko E.I. «Crystallochemical analysis of actinoids diffusion path in the structures of light rare earth monazites», Minerals: Structure, Properties, Methods of Investigation, серия Springer Proceedings in Earth and Environmental Sciences. (2019)

[3] Eremin N.N., Marchenko E.I., Mikhailova P.S., Ulanova A.S. "Theoretical evaluation of the energetics of the incorporation of plutonium impurities into phosphates with the structure of monazite, xenotime and rhabdophane", Problems of crystalology, series Issue 7, p. 16-29. (2019)

Keywords: immobilization of high-level waste, crystal structures, X-ray phase analysis 